\title{
Electrochemical Corrosion of Pb-Sn and Pb-Sb Alloys for Lead-Acid Battery Applications
}

\author{
Z. BAKOUR* AND A. DAKHOUCHE \\ Laboratory of Inorganic Materials, Faculty of Sciences, University Mohamed Boudiaf of M'sila, 28000 M'sila, Algeria

\begin{abstract}
The aim of this study was to compare the electrochemical corrosion behavior of as-cast $\mathrm{Pb}-\mathrm{Sn}$ and $\mathrm{Pb}-\mathrm{Sb}$ alloy samples in the $0.5 \mathrm{M} \mathrm{H}_{2} \mathrm{SO}_{4}$ solution at $25^{\circ} \mathrm{C}$. Electrochemical impedance spectroscopy (EIS) diagrams, potentiodynamic polarization curves and the equivalent circuit analysis were used to evaluate the electrochemical corrosion response. It was found that $\mathrm{Pb}-1$ wt.\% Sn alloy exhibits a microstructure with large cellular array and better electrochemical corrosion resistance than that of $\mathrm{Pb}-1$ wt.\% $\mathrm{Sb}$.
\end{abstract}

DOI: 10.12693/APhysPolA.134.103

PACS/topics: corrosion, lead-acid battery, microstructure, alloys

\section{Introduction}

$\mathrm{Pb}-\mathrm{Sn}, \mathrm{Pb}-\mathrm{Sb}$ and $\mathrm{Pb}-\mathrm{Ca}-\mathrm{Sn}$ alloys are commonly used in the production of positive and negative grids, of both the valve-regulated lead-acid (VRLA) and the starting, lighting and ignition (SLI) batteries [1, 2]. It is well known that the use of $\mathrm{Sb}$ (e.g. at positive SLI battery grids) enhances electrolysis of water into hydrogen and oxygen during charging, leading to water or electrolyte loss. According to [3-5], $\mathrm{Pb}-\mathrm{Sn}$ and $\mathrm{Pb}-\mathrm{Sn}(\mathrm{Ca})$ alloys appear to be a good alternative for decreasing water decomposition. It was reported [1] that $\mathrm{Pb}-\mathrm{Sb}$ alloys corrode more rapidly than $\mathrm{Pb}-\mathrm{Sn}$.

\section{Experimental procedure}

Pb-1 wt.\% Sn and Pb-1 wt.\% Sb binary alloys were prepared using commercially pure metals: $\mathrm{Pb}$ (99.89 wt.\%), Sn (99.99 wt.\%) and Sb (99.33 wt.\%). The alloys were melted in a crucible at $350^{\circ} \mathrm{C}$ and $600^{\circ} \mathrm{C}$, respectively in an electrical furnace for $30 \mathrm{~min}$, and maintained under these conditions for $1 \mathrm{~h}$ to form a homogeneous $\mathrm{Pb}-$ 1 wt.\% Sn and Pb-1 wt.\% Sb alloys. These alloys were cast into a cylindrical mold with diameter of $15 \mathrm{~mm}$ and length of $10 \mathrm{~mm}$. The cooling for both alloys was carried out in air.

As-cast specimens were sectioned through the center of the ingot, ground, polished and etched to reveal the macrostructure. A mixture of citric acid and ammonium molybdate 250 and $100 \mathrm{~g}$, respectively, for $1 \mathrm{l}$ of water was used as the etchant.

The samples were polished and etched by using $37 \mathrm{~cm}^{3}$ of glacial acetic acid and $15 \mathrm{~cm}^{3}$ of $\mathrm{H}_{2} \mathrm{O}_{2}$ solution at room temperature for microscopy examination. The microstructural characterization was carried out by using an optical microscope associated with an image processing system (A59.2207 digital camera of eyepiece type).

*corresponding author; e-mail: bakourrachda@yahoo.fr
In order to evaluate the electrochemical corrosion behavior of the Pb-1 wt.\% Sn and Pb-1 wt.\% Sb alloys, electrochemical corrosion tests were performed on a $1.32 \mathrm{~cm}^{2}$ circular area.

The surface of the lead electrode was mechanically polished with 800, 1500 and 2000 grade SiC emery paper.

Electrochemical impedance spectroscopy (EIS) measurements began after an initial delay of $35 \mathrm{~min}$, which was needed for the samples to reach a steady-state condition. The tests were carried out with the samples immersed in $250 \mathrm{~cm}^{3}$ of a stagnant and naturally aerated $0.5 \mathrm{M} \mathrm{H}_{2} \mathrm{SO}_{4}$ solution at $25^{\circ} \mathrm{C}$. A potentiostat/galvanostat (Voltalab ${ }^{\circledR}$ PGZ 402) controlled by VoltaMaster 4 software, a glass corrosion cell kit with a pure $\mathrm{Pb}$ counter-electrode and a $\mathrm{Hg} / \mathrm{Hg}_{2} \mathrm{SO}_{4} / \mathrm{K}_{2} \mathrm{SO}_{4}$ saturated reference electrode (MSE) were used to perform the EIS tests. The potential amplitude was set to $10 \mathrm{mV}$ peak-to-peak (AC signal), with ten points per decade. The frequency range was set from $100 \mathrm{mHz}$ to $100 \mathrm{kHz}$.

Potentiodynamic measurements were also carried out in the aforementioned solution at $25^{\circ} \mathrm{C}$ using the same potentiostat. These tests were performed by stepping the potential at a scan rate of $10 \mathrm{mV} \mathrm{s}^{-1}$ from $-1200 \mathrm{mV}$ (MSE) to $1200 \mathrm{mV}$ (MSE). Tafel plots using both anodic and cathodic branches at a scan rate of $10 \mathrm{mVs}^{-1}$ from $-1200 \mathrm{mV}$ (MSE) to $+0 \mathrm{mV}$ (MSE) were plotted using potentiodynamic polarization curves. In order to give quantitative support to our discussion of these experimental EIS results, an appropriate model (ZView version 2) for equivalent circuit quantification was used.

\section{Results and discussion}

\subsection{Microstructure of alloys}

Optical micrographs of the $\mathrm{Pb}-1$ wt.\% $\mathrm{Sn}$ and $\mathrm{Pb}-$ 1 wt.\% Sb alloys, are shown in Fig. $1 \mathrm{a}$ and b, respectively. The morphology structure of Pb-1 wt.\% Sn and $\mathrm{Pb}-1$ wt.\% Sb alloys obtained using given cooling rate is similar. Both alloys contain large-size grains with anomalous grain boundaries. The as-cast microstructure consists of a completely cellular array with different cell sizes. 
The $\mathrm{Pb}$-rich cellular matrix is represented by light regions and the grain boundaries are represented by dark lines.

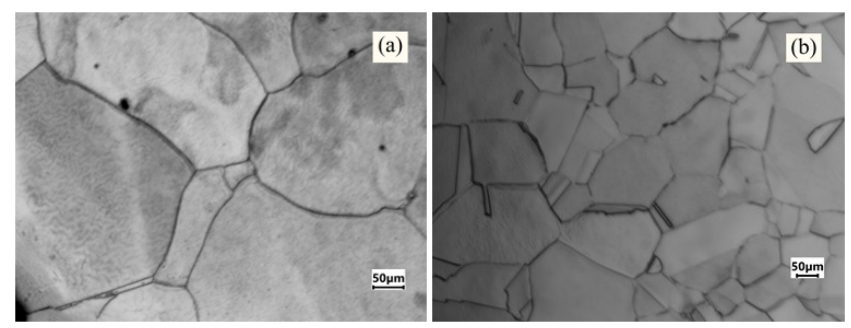

Fig. 1. Typical cellular morphologies of the cross sections of the castings of (a) Pb-1 wt.\% $\mathrm{Sn}$ and (b) $\mathrm{Pb}$ 1 wt.\% Sb alloys.

It is clear that $\mathrm{Pb}-1$ wt.\% Sn alloy Fig. 1a develops a microstructure with a larger grain size than that in the case of $\mathrm{Pb}-1$ wt.\% Sb, Fig. 1b. The average grain size is $200-250 \mu \mathrm{m}$ for $\mathrm{Pb}-1$ wt.\% $\mathrm{Sn}$ and $120-160 \mu \mathrm{m}$ for $\mathrm{Pb}-1$ wt.\% Sb.

\subsection{Electrochemical corrosion tests}

The results from the potentiodynamic polarization curves exhibiting the current densities and corrosion potentials of $\mathrm{Pb}-1$ wt.\% $\mathrm{Sn}$ and $\mathrm{Pb}-1$ wt.\% $\mathrm{Sb}$ alloys in $0.5 \mathrm{M} \mathrm{H}_{2} \mathrm{SO}_{4}$ solution at $25^{\circ} \mathrm{C}$ are shown in Fig. 2 .

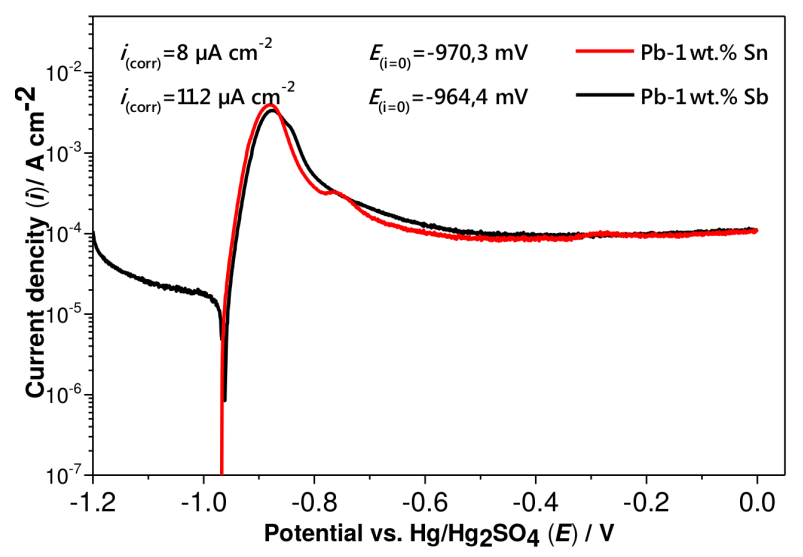

Fig. 2. Potentiodynamic polarization curves for $\mathrm{Pb}-$ 1 wt.\% $\mathrm{Sn}$ and Pb-1 wt.\% Sb alloys obtained by air casting. The curves were measured in $0.5 \mathrm{M} \mathrm{H}_{2} \mathrm{SO}_{4}$ solution at $25^{\circ} \mathrm{C}$.

The current densities and corrosion potentials for both alloys are reported in Fig. 2. For both alloys, the corrosion potential is almost constant: about $-967 \pm 3 \mathrm{mV}$. From the curves we can see that the corrosion current density depends on the nature of the alloying element. Pb-1 wt.\% Sn exhibits small corrosion current density $\left(8 \mu \mathrm{Acm}^{-2}\right)$ in comparison with that for $\mathrm{Pb}-1 \mathrm{wt} . \% \mathrm{Sb}$ $\left(11.2 \mu \mathrm{Acm}^{-2}\right)$. This means that $\mathrm{Sn}$ at level of $1 \mathrm{wt} . \%$ exhibits good electrochemical corrosion resistance.

\subsection{EIS and equivalent circuit analysis}

Experimental Nyquist diagrams for Pb-1 wt.\% Sn and $\mathrm{Pb}-1$ wt.\% $\mathrm{Sb}$ measured in $0.5 \mathrm{M}$ aqueous solution of $\mathrm{H}_{2} \mathrm{SO}_{4}$ at $25^{\circ} \mathrm{C}$ are given in Fig. 3 .

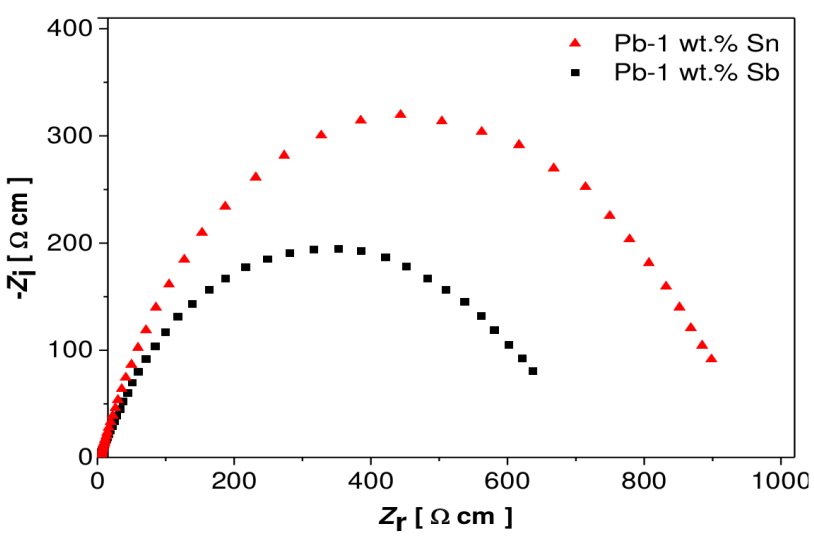

Fig. 3. Nyquist diagrams of the experimental results for $\mathrm{Pb}-1$ wt.\% $\mathrm{Sn}$ and $\mathrm{Pb}-1$ wt.\% $\mathrm{Sb}$ in the $0.5 \mathrm{M} \mathrm{H}_{2} \mathrm{SO}_{4}$ solution at $25^{\circ} \mathrm{C}$.

Nyquist plots show that the diameter of the capacitive semi-circle for $\mathrm{Pb}-1 \mathrm{wt} \% \mathrm{Sn}$ is higher that that of $\mathrm{Pb}-1$ wt.\% Sb which means that tin provides a better corrosion resistance of the alloy then the antimony.

Figure 4 depicts the Bode and Bode-phase diagrams representing the phase angle $\theta$ and modulus of impedance $|Z|$ as functions of frequency.

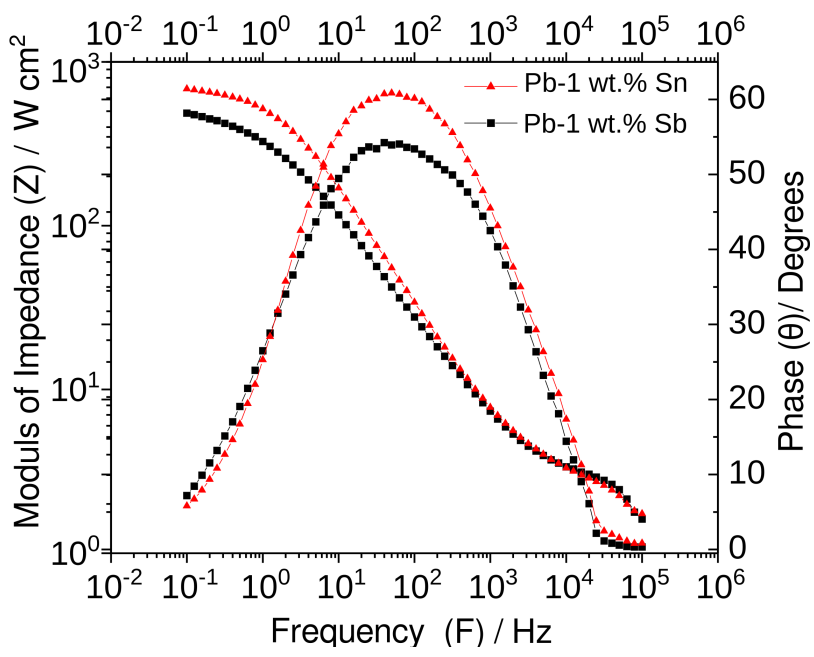

Fig. 4. Experimental EIS diagrams (Bode and Bodephase) of Pb-1 wt.\% Sn and Pb-1 wt.\% Sb in the $0.5 \mathrm{M}$ $\mathrm{H}_{2} \mathrm{SO}_{4}$ solution at $25^{\circ} \mathrm{C}$.

The maximum moduli of impedance $|Z|$ of $\mathrm{Pb}-$ 1 wt.\% $\mathrm{Sn}$ and $\mathrm{Pb}-1$ wt.\% $\mathrm{Sb}$ alloys are 684 and $486.7 \Omega \mathrm{cm}^{2}$, respectively at $0.1 \mathrm{~Hz}$. Considering the Bode-phase diagrams, the maximum phase angles $\theta_{\max }$ of about $60.84^{\circ}$ at the frequency of $50 \mathrm{~Hz}$ and $54.24^{\circ}$ at $40 \mathrm{~Hz}$ are observed for the $\mathrm{Pb}-1$ wt.\% $\mathrm{Sn}$ and $\mathrm{Pb}-$ $1 \mathrm{wt} . \% \mathrm{Sb}$ alloys, respectively. 
These experimental impedance parameters give a clear indication that the $\mathrm{Pb}-1 \mathrm{wt} . \% \mathrm{Sn}$ alloy exhibits a better electrochemical behavior when compared to the results corresponding to $\mathrm{Pb}-1 \mathrm{wt} . \% \mathrm{Sb}$.

An equivalent circuit has also been proposed for fitting the experimental data (shown in Fig. 5).

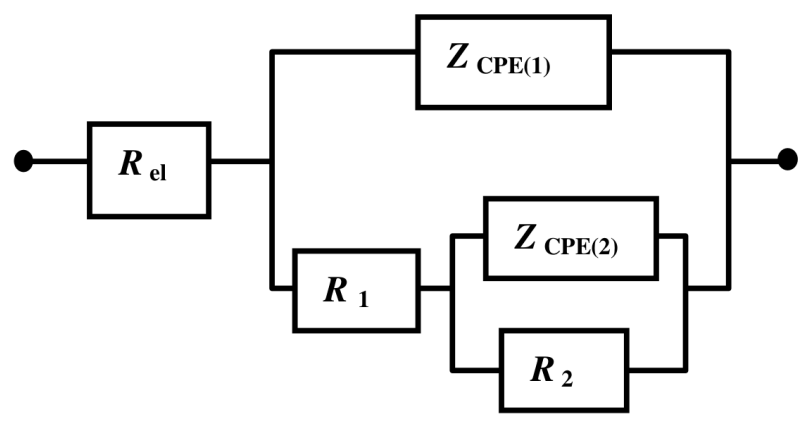

Fig. 5. The proposed equivalent circuit for impedance parameters.

The impedance parameters obtained using the ZView ${ }^{\circledR}$ software for Pb-1 wt.\% $\mathrm{Sn}$ and $\mathrm{Pb}-1$ wt.\% $\mathrm{Sb}$ alloys are shown in Table I. In the circuit, $R_{\mathrm{el}}$ denotes the electrolyte resistance which in the Bode plot is expressed in a high frequency limit $(F>1 \mathrm{kHz}), R_{1}$ is the charge transfer resistance and $R_{2}(F<0.1 \mathrm{~Hz})$ stands for the polarization resistance caused by the participation of adsorbed intermediates. $Z_{\mathrm{CPE}(1)}$ and $Z_{\mathrm{CPE}(2)}$ denote the double-layer capacitance and the capacitance associated with the polarization resistance $R_{2}$.

TABLE I

Impedance parameters obtained using ZView software by fitting the experimental results for $\mathrm{Pb}-1$ wt.\% $\mathrm{Sn}$ and $\mathrm{Pb}-1$ wt.\% $\mathrm{Sb}$ alloy samples in the $0.5 \mathrm{M} \mathrm{H}_{2} \mathrm{SO}_{4}$ solution at $25^{\circ} \mathrm{C}$.

\begin{tabular}{l|c|c}
\hline \hline \multicolumn{1}{c|}{ Parameters } & Pb-1 wt.\% Sn & $\mathrm{Pb}-1$ wt.\% Sb \\
\hline$R_{\mathrm{el}}\left[\Omega \mathrm{cm}^{2}\right]$ & 2.856 & 2.881 \\
$Z_{\mathrm{CPE}(1)}\left[\mathrm{Fcm}^{-2}\right]$ & $61.08 \times 10^{-6}$ & $23.6 \times 10^{-6}$ \\
$n_{1}$ & 0.867 & 0.9579 \\
$R_{1}\left[\Omega \mathrm{cm}^{2}\right]$ & 10.19 & 6.034 \\
$Z_{\mathrm{CPE}(2)}\left[\mathrm{Fcm}^{-2}\right]$ & $0.766 \times 10^{-3}$ & $0.5485 \times 10^{-3}$ \\
$n_{2}$ & 0.7032 & 0.6303 \\
$R_{2}\left[\Omega \mathrm{cm}^{2}\right]$ & 702.2 & 185.3 \\
$X^{2}$ & $19.87 \times 10^{-3}$ & $16.31 \times 10^{-3}$
\end{tabular}

Parameters $n_{1}$ and $n_{2}$ are correlated with the phase angle, varying between 0 and 1 . A constant-phase element representing the shift from an ideal capacitor was used for simplicity instead of the capacitance itself. The impedance of a phase element is defined as $Z_{\mathrm{CPE}}=$ $1 /\left[C(j \omega)^{n}\right] \quad[6-10]$, where $C$ is the capacitance, $j$ is the electric current, $\omega$ is the frequency and $0 \leq n \leq 1$. The value of $n$ seems to be associated with the nonuniform distribution of current as a result of surface roughness and defects.

In Table I it can be observed that $Z_{\mathrm{CPE}(1)}$ and $Z_{\mathrm{CPE}(2)}$ for coarse cellular spacing are higher than the corresponding values for fine spacing. These capacitances are also associated with the lowest resistances of $R_{1}$ and $R_{2}$, which indicate that the coarse cellular array has a better electrochemical corrosion resistance than the fine cellular structure.

\section{Conclusions}

From the obtained results, we can conclude that the microstructure is an important parameter which controls the corrosion process of alloys used in the lead-acid batteries. Tin added to lead at a level of $1 \mathrm{wt} . \%$ exhibits a rather better corrosion resistance than $1 \mathrm{wt} . \%$ of $\mathrm{Sb}$.

\section{References}

[1] R.D. Prengaman, J. Power Sources 95, 224 (2001).

[2] R.D. Prengaman, J. Power Sources 158, 1110 (2006).

[3] B. Rezaei, S. Damiri, J. Solid State Electrochem. 9, 590 (2005).

[4] M. Shiota, T. Kameda, K. Matsui, N. Hirai, T. Tanaka, J. Power Sources 144, 358 (2005).

[5] W.R. Osorio, C.S.C. Aoki, A. Garcia, J. Power Sources 185, 1471 (2008).

[6] G. Song, A. Atrens, M. Dargusch, Corros. Sci. 41, 249 (1998).

[7] L. Yu, G.L. Ding, J. Reye, S.N. Tewari, S.N. Ojha, Metall. Mater. Trans. A 30, 2463 (1999).

[8] D. Pavlov, M. Bojinov, T. Laitinen, G. Sundholm, Electrochim. Acta 36, 2087 (1991).

[9] W.X. Guo, D. Shu, H.Y. Chen, A.J. Li, H. Wang, G.M. Xiao, C.L. Dou, S.G. Peng, W.W. Wei, W. Zhang, H.W. Zhou, S. Chen, J. Alloys Compd. 475, 102 (2009).

[10] W.R. Osório, C.M.A. Freire, A. Garcia, J. Mater. Sci. 40, 4493 (2005). 